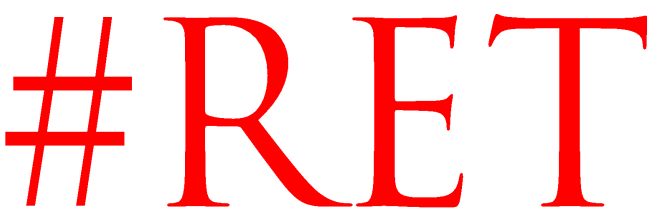

Revista Española de la Transparencia

Núm. 12. Primer Semestre. Enero-Junio de 2021, pp. 15-24

ISSN 2444-2607. www.revistatransparencia.com

DOI: https://doi.org/10.51915/ret.163

\title{
Un análisis de la Directiva (UE) 2019/1937 desde la ética pública y los retos de la implementación
}

\author{
Manuel Villoria Mendieta ${ }^{1}$ \\ Catedrático de Ciencia Política \\ Universidad Rey Juan Carlos \\ España
}

ORCID: 0000-0002-1055-1995

RECIBIDO: 14 de marzo de 2021

ACEPTADO: 14 de marzo de 2021

RESUMEN: A raíz de la Directiva europea 2019/1937 los estados miembros de la Unión Europea tendrán que poner en marcha o adaptar los sistemas de denuncia en las organizaciones públicas y privadas para garantizar la protección de los denunciantes. El autor reflexiona sobre los retos existentes para la implementación de los sistemas de denuncia.

PALABRAS CLAVE: Sistemas de denuncia, integridad, alertadores.

CONTENIDOS: 1. Introducción. - 2. La dualidad de objetivos y sus consecuencias. 3. El utilitarismo de la regla como fundamento moral de la ley española de trasposición de la Directiva. - 4. Conclusión. - Bibliografía.

\footnotetext{
${ }^{1}$ Catedrático de Ciencia Política y de la Administración de la Universidad Rey Juan Carlos de Madrid Doctor en Ciencia Política y de la Administración por la Universidad Complutense de Madrid, Licenciado en Derecho y Licenciado en Filosofía y Letras; fue becario Fulbright en Estados Unidos, donde realizó estudios de Master en Public Affairs por la Indiana University. Es Director del Observatorio de Buena Gobernanza-URJC.
} 


\section{An analysis of Directive (EU) 2019/1937 from public ethics and the challenges of implementation}

ABSTRACT: As a result of the European Directive 2019/1937, the member states of the European Union will have to implement or adapt complaint systems in public and private organizations to guarantee the protection of whistleblowers. The author reflects on the existing challenges for the implementation of complaint systems.

KEYWORDS: Reporting of breaches, Integrity, Whistleblowers. 


\section{Introducción}

La trasposición de la Directiva (UE) 2019/1937, relativa a la protección de las personas que informen sobre infracciones del Derecho de la Unión, puede suponer un aporte muy positivo para la mejora de nuestro Estado de Derecho y la lucha contra la corrupción en España. Pero la consecución de impactos positivos de las normas y decisiones adoptadas en el marco de políticas públicas complejas, como esta del reforzamiento del Estado de Derecho, requiere no sólo de normas muy bien redactadas técnicamente, sino también de normas que anticipen todos los retos de implantación que la llegada de una norma de este tipo genera en el sistema político-administrativo. El reto de la implementación de esta norma va a ser enorme. Como ya nos indicaron Pressman y Wildavsky, cuanto más actores existan y más alejados del centro de decisión estén, más posibles puntos de veto y espacios de negociación existirán y más dificil será que la política alcance plenamente los objetivos para los que nació (1984). Esta norma afecta a miles de organizaciones, a millones de personas insertas en tipos de organizaciones muy diversos y conlleva un cambio organizativo y cognitivo bastante profundo. La implementación puede cambiar completamente el objetivo de una política, sus prioridades y sus pretendidas consecuencias. En ella, caben reglamentos, órdenes, decisiones administrativas, sentencias judiciales, el cumplimiento, incumplimiento o cumplimiento parcial por los destinatarios, los impactos percibidos y las revisiones de lo que se va haciendo en función de consecuencias imprevistas, efectos indeseados o de los análisis evaluativos que van proporcionando datos sobre el "implementation gap" (Hill y Hupe, 2002). Por todo ello, creemos que es importante estudiar los retos de implementación que una norma de estas características genera.

De todos los retos de implantación vamos a centrarnos en uno de ellos, el que tiene que ver con la claridad de los objetivos. Para la adecuada implementación de una política pública es importante que las normas en que se fundamenta tengan objetivos claros y una teoría causal sólida (Sabatier \& Mazmanian, 1980). Como veremos en este texto, se puede demostrar que los objetivos de la normativa que viene de Europa y su teoría causal tienen un cierto nivel de confusión. Aunque la Directiva se titula como de protección a las personas que informen sobre infracciones del Derecho de la Unión, el objetivo es doble, por una parte, el de protección de la aplicación del derecho de la Unión o el aseguramiento del Estado de Derecho en la UE, por otra, la protección a los informadores. Si se analiza en profundidad, se verá que los dos objetivos podrian llevar a regulaciones diferentes. En principio, es un acierto el conectarlos, pues de la sinergia surgirán beneficios para el logro de ambos, pero esto no impide contradicciones que sería bueno señalar. 


\section{La dualidad de objetivos y sus consecuencias}

Como acabamos de indicar, la Directiva es de protección de alertadores y denunciantes, pero también es una norma que trata de fomentar el respeto de las leyes. En principio, esta doble opción es lógica, pero tiene tensiones internas que convendría resolver. Una normativa que intente proteger el cumplimiento de la ley debería sustentarse en abrir canales de denuncia anónimos y, sobre todo, en asegurar una rigurosa investigación de los hechos denunciados. La protección a los alertadores podria quedar en un nivel secundario en este supuesto. Si la ley lo que quisiera, por el contrario, es proteger a los alertadores, entonces la investigación de las denuncias no sería prioritaria, pues bastaría con la existencia en los alertadores de "motivos razonables para creer, a la luz de las circunstancias y de la información de que dispongan en el momento de la denuncia, que los hechos que denuncian son ciertos", como indica la directiva, para que se activaran los mecanismos de protección, que sería lo realmente importante. Dicho esto, la Directiva conecta ambos objetivos con la explicación siguiente: si se quiere asegurar el cumplimiento del derecho se necesitan denuncias de los incumplimientos, pero no habrá suficientes denuncias si no se protege a los denunciantes. A nuestro juicio, esta justificación es excesivamente simplista y genera algunas preguntas, como la de si es legítimo asegurar el cumplimiento del derecho incentivando denuncias fundadas en venganzas, envidias o luchas de poder. En última instancia, si el fin justifica los medios.

En general, esta justificación de la norma es claramente utilitarista (García Moreno, 2020), la protección de los denunciantes se hace para que surjan denuncias, al surgir denuncias se producirá un doble efecto positivo; por una parte, se investigarán y sancionarán las infracciones, por otra, el miedo a ser denunciado reducirá los incentivos para la infracción, con todo ello, la economía europea será más competitiva y la protección de los derechos ciudadanos será más eficaz. Al optar por el utilitarismo, la protección al denunciante no tiene que basarse en criterios deontológicos, como los derechos humanos o la protección a quien actúa en defensa del bien común con independencia de las consecuencias. Se puede proteger a cualquier persona que denuncie, aunque lo haga por motivos indignos, como la venganza, la envidia o el reparto inequitativo del botín, pues la clave es que con ello se ayuda a la propia empresa y al interés general, mediante la protección de la seguridad financiera en los mercados, el aseguramiento de la conformidad a la ley y a las normas vigentes, la prevención del fraude, etc. (Goñi Sein, 2011). Más aún, siendo coherentes con la moralidad del fin perseguido, se deben estimular las denuncias entre compañeros o conciudadanos por medios diversos (imposición de deberes, recompensas económicas, ofrecimiento de protección jurídica, etc.) (Ragués Vallés, 2013); es cierto que, con ello, los denunciantes son utilizados como medios, no como fines, que es como debe ser tratada cualquier persona a la que se reconoce dignidad de acuerdo con la teoría 
kantiana, pero las consecuencias mandan, el fin lo justifica. Se les protege porque nos interesa, más allá de su derecho a la protección. Si siguiéramos esta argumentación hasta el final, lo normal sería que se premiara a los denunciantes, pues sería la forma más clara de obtener denuncias ante cualquier infracción (Dworkin, 2007, 1779-80; Verschoor, 2017; Cerrillo, 2019). Y, además, sería lógico que no se sancionara duramente a quienes hacen denuncias que se comprueban después como insostenibles, pues ello podría desincentivar la denuncia cuando la situación no es absolutamente clara y dejarnos sin conocer situaciones que son negativas para el bien común (sin por ello tener que incentivar la denuncia falsa, que implica costes y desmoralización en las organizaciones).

Pero la misma directiva que acoge la argumentación utilitarista, asume también criterios deontológicos en su justificación. En su exposición de motivos, la directiva establece que "las personas que comunican información sobre amenazas o perjuicios para el interés público, obtenida en el marco de sus actividades laborales, hacen uso de su derecho a la libertad de expresión. El derecho a la libertad de expresión y de información, consagrado en el artículo 11 de la Carta y en el artículo 10 del Convenio Europeo para la Protección de los Derechos Humanos y de las Libertades Fundamentales, incluye el derecho a recibir y comunicar informaciones, así como la libertad y el pluralismo de los medios de comunicación". Más adelante insiste: "es necesario proteger la revelación pública de información, teniendo en cuenta principios democráticos tales como la transparencia y la rendición de cuentas, y derechos fundamentales como la libertad de expresión y la libertad y el pluralismo de los medios de comunicación". En estos supuestos, lo que existe es un componente deontológico, se protegen derechos fundamentales universales, vinculados al principio de la dignidad humana. Siendo coherentes con este enfoque, lo normal es que no se hiciera referencia a la utilidad o no de la protección, pues aunque no tuviera consecuencias positivas habria que defenderla por su moralidad intrínseca. No podemos permitir que se acose o se haga la vida imposible a alguien que denuncia porque cree que con ello defiende el bien común. Del mismo modo, debería evitarse y, si se diera, sancionarse con todo rigor la denuncia malintencionada y falsa, al atentar también contra la dignidad de la persona humana; más aún, los canales de denuncia deberían superar el juicio de proporcionalidad stricto sensu, dado que los limites que pueden sufrir los investigados en virtud del whistleblowing no deben desarrollarse de forma desproporcionada respecto de sus derechos fundamentales (Pérez Triviño, 2018, 296).

Tras este análisis de la teoría causal, podemos concluir que la Directiva se queda en un camino intermedio que no aclara muy bien qué enfoque predomina y cómo interpretar ciertas incongruencias. Si se cree que predomina el enfoque utilitarista, entonces no está nada claro por qué apenas se trata el tema de la investigación de las denuncias (Sierra, 2020a: 78; 2020b) y se deja en la nebulosa de la legislación interna, o por qué no se establecen sistemas de premios para las denuncias que promueven la eficiencia, aunque genere rechazo moral desde visiones 
deontológicas (Berger et al. 2017). Cuando lo que importa son las consecuencias, es absolutamente prioritario investigar bien toda denuncia y sancionar de forma rigurosa el incumplimiento. Pero si predominara el enfoque deontológico, entonces no se explica muy bien que se anime a denunciar por todo tipo de razones, muchas de las cuales serían contrarias al imperativo categórico. Desde esta teoría, no se pueden fomentar conductas contrarias a principios éticos universales porque sean útiles a la sociedad. Ante estas contradicciones, creemos que, de cara a justificar éticamente la norma, sería mejor optar claramente por una visión utilitarista, pero fundada en el utilitarismo de la regla, no en el del acto, con ello se evitarían ciertas contradicciones y la interpretación de la norma sería más sencilla. Esta idea es sobre todo importante para el adecuado funcionamiento de la norma en el sector privado.

\section{El utilitarismo de la regla como fundamento moral de la ley española de trasposición de la Directiva.}

Según el utilitarismo del acto, una acción justa o correcta es aquella que tendría buenas consecuencias, dadas las circunstancias en que se desarrolla la acción. De acuerdo con esta posición, se juzgaría cada acción solo en términos de sus efectos. El utilitarismo de la regla, en cambio, puede prohibir hacer algo que tenga las mejores consecuencias. Según esta concepción hay reglas útiles que, si se observan en general, facultan a la gente a predecir la conducta de los demás, así como a una comunidad a crear las mejores consecuencias. Estas reglas definen lo justo y lo injusto y deben juzgarse los actos comprobando si están de acuerdo con estas reglas morales o las transgreden. Stuart Mill (1863) piensa que, a veces, es necesario el bien de un acto en particular. En otras ocasiones no es necesario y basta actuar según la virtud a la que pertenece una regla determinada. Hay reglas que la historia nos demuestra que, si se siguen, producen más bien al mayor número, y cuando estamos frente a un dilema lo que hay que hacer es seguirlas, no analizar en ese caso si su incumplimiento podría producir más bien.

El utilitarismo, en sus versiones de la regla (Harsanyi, 1999), considera que los seres humanos tienen dos preocupaciones básicas -y racionales-: una es su propio bienestar y la otra es el bienestar de los demás, empezando por los más cercanos. Pero lo que cualquier ser racional entenderá es que, viviendo en sociedad, centrarse en el bienestar propio o de los cercanos a cambio de generar daño colectivo no es una regla que se pueda seguir sin la destrucción de la sociedad y, con ello, de nuestro propio bienestar. La dimensión moral en una sociedad se hace posible por la igual consideración de todos sus miembros; en expresión de Bentham: "todo el mundo cuenta por uno, nadie por más de uno", sentencia que ha sido citada en numerosas ocasiones no solo por los moralistas utilitaristas sino también de otras escuelas. Mill, a propósito de esta idea, observa que el principio de utilidad solo tiene sentido si la felicidad de una persona cuenta exactamente lo mismo que la de otra persona. Partiendo de la idea de que la norma de la ética utilitarista no se reduce a la felicidad individual del agente, sino que debe tener en 
cuenta la de todos los individuos implicados en las consecuencias de las acciones, Mill considera la situación o la perspectiva en que la moral sitúa al individuo cuando actúa moralmente. Ser uno entre muchos, ser uno más: "el utilitarismo exige a cada uno que entre su propia felicidad y la del resto sea un espectador tan estrictamente imparcial como desinteresado" (Mill, 1864, cap., 2, p. 24), lo que viene a desembocar en la norma áurea de la moral, es decir, "compórtate como querrias que se comportaran contigo", lo que lleva, a su vez, al carácter compulsorio de las normas morales y, por ende, a su universalidad.

Las reglas morales óptimas son aquellas que sean capaces de producir los máximos beneficios a la sociedad, juzgada desde un punto de vista moral, equitativo e imparcial. En términos técnicos, las reglas morales óptimas serian aquellas que maximicen la utilidad social esperada -principio de la utilidad social. La utilidad social sería la media aritmética de los niveles de utilidad de todos los individuos de una sociedad, aunque algunos utilitaristas la definen como la suma de los niveles de utilidad. En suma, para el utilitarismo de la regla una acción moralmente correcta es aquella que concuerde con un código moral óptimo; un código óptimo es aquél que nos produciría el máximo nivel de utilidad esperada, si fuese cumplido por todos los miembros de la sociedad, o al menos por los más responsables. Dicho esto, si lo que la Directiva está promoviendo es el utilitarismo del acto, entonces, cualquier empresario, ante el dilema de respetar las reglas abstractas del mercado justo o promover los intereses de la empresa, sobre todo en momentos de crisis, buscará satisfacer sus propias preferencias y, a menos que vea claramente que el incumplimiento de las normas pone en riesgo su libertad o a su empresa, podrá llegar a pagar sobornos o fijará precios con la competencia para subsistir. Del mismo modo, un político, ante el dilema de perder el poder o represaliar a un denunciante y evitar que su denuncia salga a luz, generará un utilitarismo ad hoc que a él le sirva para justificar su acción, por ejemplo, destacando la maldad de la oposición y su peligro para el bien común.

Centrándonos en el sector privado, las empresas es cierto que tienen que ser rentables o, al menos, sostenibles, pues sin ello no podrán cumplir su misión, pero guiarse por la búsqueda de rentabilidad no basta para que el sistema de mercado funcione. Si el mercado ignora a la sociedad en la que opera y rompe sus propias reglas del juego -esencialmente la competencia justa- tendrá un impacto negativo en su propia actividad y, en última instancia, atentará contra su propia supervivencia, como acabamos de ver en la Gran Depresión; finalmente, cuando llegue la crisis, será necesaria la intervención pública para salvar al propio mercado de sus excesos (Polanyi, 2002), eso sí, con dinero de todos. Para evitar estas tensiones destructivas, el mercado debe entenderse como parte del sistema social y, por tanto, como un socio clave en el desarrollo del valor social y de las políticas económicas que sirven esencialmente al bien común. El valor social implica productos y resultados no financieros, es decir, intervenciones que implican a las personas, las comunidades, el capital social y el medio ambiente y que mejoran el bienestar social (Porter y Kramer. 2011; Mulgan, 2010). Por eso es importante incluir 
una dimensión moral en la toma de decisiones en este ámbito, más compleja que el utilitarismo mal entendido o utilitarismo ad hoc (Sandin, 2009). Desde un punto de vista económico, y respetando la noción de que el hombre persigue su propia felicidad y huye del dolor, sería necesario, a través de la educación, introducir el utilitarismo de la regla en el sistema para las decisiones empresariales de esta naturaleza, ya que: "Permite que un acto particular en una ocasión particular sea adjudicado como correcto o incorrecto según si está de acuerdo con una regla útil - la viola; y una regla se juzga útil o no por las consecuencias de su práctica general" (Duignan y West, 2017).

Esto implicaría que los actores económicos -como principio de conducta en este tipo de dilema- buscarán el mayor bien para el mayor número de personas sin hacer un balance de los beneficiados o perjudicados por cada acción, si no, más bien, siguiendo las reglas que la historia y la calidad de los resultados han demostrado que producen el mayor bien para el mayor número de personas (Mill, 1863: 35-37). Como quiera que la competencia justa es una regla clave para el buen funcionamiento del mercado, promover y asumir este modelo de reflexión moral parece esencial para el adecuado funcionamiento de un buen modelo de ética en la empresa. Esto significa que hay que asumir que el respeto a las reglas de la competencia leal (tal y como la entienden la mayoria de los estudiosos de la ética empresarial en la actualidad) conduce a un mayor bien social que romper dichas reglas y generalizar el juego sucio. En conclusión, a menos que las reglas entren en conflicto entre ellas, es mejor seguirlas, sin siquiera calcular las consecuencias, que sopesar el respeto a las reglas con el beneficio inmediato para la empresa. Mientras este nivel de desarrollo moral no sea generalizado en el mundo empresarial, y se manifieste en una cultura organizativa donde el liderazgo ético y la responsabilidad social estén profundamente insertos, es muy difícil que la mera gestión interna de denuncias pueda producir resultados positivos (Trevino et al., 1999).

\section{Conclusión}

Resumiendo, se protege a los denunciantes porque el respeto a derechos humanos básicos como la libertad de expresión y el respeto a la libertad de prensa producen mayores bienes para el conjunto de la ciudadanía que lo contrario, la represión de la libre opinión o de la libre circulación de información. La historia lo ha demostrado, pues los paises que han consolidado derechos humanos generan más bienestar y riqueza colectiva que aquellos sometidos a dictadura. Al tiempo, se protege a los denunciantes porque la competencia justa es la esencia de un mercado eficiente y generador de riqueza, y porque el respeto al Derecho genera una cultura de la legalidad que aporta certidumbre, seguridad jurídica y equidad. Es cierto que existe una crítica posible a esta opción, sobre todo si se analiza desde el sector público y se recuerdan los deberes de cuidado, empatía y solidaridad (Gilligan, 1985) que los funcionarios deben incorporar a su comportamiento. Pero no olvidemos que tenemos que construir una justificación que sirva al sector público y 
privado, y, en ese caso, creemos que esta opción por un utilitarismo de la regla supera mejor las objeciones que el apoyo a las otras dos opciones (utilitarismo del acto y deontología) nos deparan.

\section{Bibliografía.}

Berger, L., S. Perreault and J. Wainberg. 2017. Hijacking the moral imperative: How financial incentives can discourage whistleblower reporting. Auditing: A Journal of Practice \& Theory 36(3): 1-14.

Cabanes, Manuel (2016) La misión de la empresa como objetivo supremo de la misma: análisis discursivo y mirada prospectiva. 189-216 Icade. Revista cuatrimestral de las Facultades de Derecho y Ciencias Económicas y Empresariales, $\mathrm{n}^{\circ}$ _99 septiembre-diciembre 2016: 189-216

Cerrillo i Martínez, A. (2018). Diez propuestas para la colaboración ciudadana en la alerta de malas prácticas en la Administración Pública. Revista Internacional de Transparencia, 6, pp. 1-7.

Diugnan, B and H. R. West (2017) "Utilitarianism". Encyclopæedia Britannica. Encyclopæedia Britannica, inc., date Published: November 15, 2017, URL: https://www.britannica.com/topic/utilitarianism-philosophy. Access Date: September 7, 2018.

Dworkin,. T. M. (2007). SOX and Whistleblowing. Michigan Law Review Volume 105 Issue 8: 1757-1780.

Garcia Moreno, B. (2020). Del whistleblower al alertador. La regulación europea de los canales de denuncia. Valencia: Tirant Lo Blanch.

Gilligan, C. (1985). La moral y la teoria: Psicología del desarrollo femenino. México D.F: Fondo de cultura económica de México

Goñi Sein, J.L. (2011). "Sistemas de denuncia interna de irregularidades ("whistleblowing"). En: Goñi Sein, J.L., Ética empresarial y códigos de conducta, Madrid, La Ley, pp.319-355

Harsanyi, J. (1999) "Razón, moralidad y teoría utilitarista", en VV.AA., Decisiones normativas en los campos de la ética, el estado y el derecho, Destino, Caracas.

Hill, M. y Hupe, P. (2002) Implementing Public Policy: Governance in Theory and in Practice. London: Sage

Mill, John Stuart (1863) Utilitarianism (1 ed.). London: Parker, Son \& Bourn, West Strand. Retrieved April 6, 2018 via Google Books 
Mulgan, G. (2010) "Measuring Social Value." Stanford Social Innovation Review, (Summer): 38-43.

Pérez Triviño, J.L., "Whistleblowing”, Eunomia, núm. 14, 2018: 285 y 298.

Polanyi, K. (2002) The Great Transformation: The Political and Economic Origins of Our Time. Boston: Beacon Press.

Porter, M. \& Kramer, M. (2011) Creating Shared Value. Harvard Business Review, 89 , pp. 62-77.

Pressman, j y Wildavsky, A. (1984) Implementation: How Great Expectations in Washington Are Dashed in Oakland. Berkeley: University of California Press.

Raguès Vallès, R., (2013) Whistleblowing. Una aproximación desde el Derecho Penal, Madrid: Marcial Pons.

Sabatier, P. y D. Mazmanian (1980) The implementation of public policy: a framework of analysis. Policy Studies Journal, Volume 8, Issue 4, January 1980: $538-560$

Sandin, Per (2009) Approaches to Ethics for Corporate Crisis Management. Journal of Business Ethics volume 87, 109 (2009) https://doi.org/10.1007/s10551-0089873-2.

Sierra Rodríguez, J. (2020a). Impulso europeo al whistleblowing y las autoridades de integridad. Eunomía. Revista en Cultura de la Legalidad, 19, pp. 64-85.

Sierra Rodríguez, J. (2020b) Anonimato y apertura de los canales de denuncia de la corrupción. Revista General de Derecho Administrativo 55 (lustel)

Trevino, L., Weaver, G. R, Gibson, D., \& Toffler, B. (1999). Managing ethics and legal compliance: What works and what hurts. California Management Review, 41(2), 131-150.

Verschoor, C. C. 2017. Whistleblower awards increase. Strategic Finance (April): 2324. 